\title{
SOCIAL WORK SUPERVISION POLICIES AND FRAMEWORKS: PLAYING NOTES OR MAKING MUSIC?
}

\section{Lambert Engelbrecht}

\section{INTRODUCTION}

Kadushin (1992:230-231) drew a parallel between the supervision of social workers and making music: is supervision just a random sounding of notes, serving to mask incompetence, or is it tuneful music, conducive to social workers' best efforts? This analogy may be considered to reflect the emergence of new public management measures as an operationalisation of neoliberal ideas, with consequent changes in conditions of service delivery, control and accountability of social workers. These management mechanisms for bureaucratic standardisation in social work have resulted in, for example, the introduction of supervision policies and frameworks in various countries, such as those of the Australian Association of Social Workers (2010), British Association of Social Workers (2011), Aortearoa New Zealand Association of Social Workers (2012), and the supervision framework for the social work profession in South Africa (DSD \& SACSSP, 2012), to name a few.

Contradictory viewpoints emerge when some scholars resist managerialism and others advocate increasing control over supervision practices in social work, as elucidated by Lambley (2010). Such conflicting ideas are seldom accommodated as mainstream topics in social work deliberations. This state of affairs prompted research with the aim to delineate prevailing issues and challenges in supervision of social workers in South Africa, despite and beyond the introduction of a national standardised supervision framework for social workers of the country. The South African social work fraternity was selected as an instrumental case study, as described by Fouché (2005), because homogeneous professional, statutorily regulated public and private social work and supervision practices are employed within the country's social development approach towards social welfare services, as imposed by the Social Service Professions Act (RSA, 1978) and the Government's Integrated Service Delivery Model for Social Service Delivery (DSD, 2006b).

By means of qualitative research findings this paper draws attention to the fact that despite managerial endeavours to progressively introduce supervision policies and frameworks to ensure evidence-based practices, several issues detrimental to the quality of supervision may still recur. Pertinent challenges remain beyond circumscribed do's and don'ts of normative supervision policies and frameworks. These findings can be extrapolated beyond specific organisational contexts in order to fortify supervision of social workers and ultimately the social work profession in South Africa.

\section{BACKGROUND TO THE STUDY}

The South African Department of Social Development (DSD) and the South African Council for Social Service Professions (SACSSP) substantiate the rationale for supervision of social workers in their supervision framework for the social work 
profession (DSD \& SACSSP, 2012) with an assertion by Botha (2002), one of the pioneers of social work supervision in South Africa, that it is especially the unpredictable, non-routine, non-standardised, highly individualised and imperceptible nature of social work practice which necessitates supervision. In addition, several statutory requirements of social work practices in South Africa, such as the Social Service Professions Act (RSA, 1978), Code of Ethics (SACSSP, 2007) and the Children's Act, No. 38 of 2005 (RSA, 2006), provide a mandate for supervision of social workers. The South African supervision framework furthermore derives from "the perceived need for effective supervision within the social work profession in order to improve quality social work services offered to service users" and "it is informed by, amongst other things, lack of adequate training, structural support and unmanageable workloads" (DSD \& SACSSP, 2012:14). The rationale for this framework is furthermore based on Botha's (2002:1) postulation that "the problem, however, does not lie with supervision practice or the nature thereof, but the fact that supervision applied is either faulty or weak". In order to counteract this "faulty or weak" application of supervision, the South African supervision framework offers a conceptual and contextual framework, which is supposed to serve as basis for the framework's explicitly formulated norms and standards on supervision.

Although the framework states that the intention is not to provide a comprehensive theoretical exposition of supervision, that it does not purport to be a training manual or academic text, and that it would be unscholarly and a negation of social work's heritage of a professional body of knowledge to encapsulate the theoretical foundations of supervision within a single framework, yet the conceptualisation and contextualisation of the theoretical foundation of supervision in the framework does exactly that. For example: supervision of social workers and related concepts are defined by means of a compilation of different literature sources, without citing them and without revealing the specific country's welfare policy contexts that have moulded and underlie these literature sources. These sources furthermore emanate mostly from clinical supervision contexts, which may be regarded as the exact opposite of South Africa's developmental social welfare policy paradigm (DSD, 2006b; Engelbrecht, 2010a). Moreover, the framework refers to distinct theories, models and perspectives undergirding the essence of supervision, without defining these concepts, nor clarifying or indicating how situational or institutional contexts determine these theories, models and perspectives, and how they direct the definition of supervision. This tendency is also pursued and evident in the framework's descriptions of the roles and responsibilities of supervisors and supervisees, and in related expounded concepts such as principles, functions, phases of supervision and even supervision styles. Hence quality evidence-based practice is ironically promoted by the South African supervision framework by means of contentious substantiation.

The DSD and SACSSP rightly assume, as Carpenter, Webb, Bostock and Coomber (2012b:3) observe, that supervision is a "good thing", but maintain the notion that standardised supervision norms on a national level will simply and automatically improve the quality of practice. In this regard, Bogo and McKnight (2005:56) conclude 
that the conceptualisation of social work supervision is an organisational function and particularly that "its forms and functions emanate from the organisation's mandate in order to shape the nature of supervision". To define supervision as a "good thing" thus certainly requires acknowledgment of a country's welfare policy paradigm, institutional contexts and grounded research, and not just randomly adopting international, favourable common theoretical constructs by means of standards into a normative framework for supervisors.

The South African supervision framework's negation of the impact of the country's welfare policy paradigm and institutional contexts on the definition of supervision, conceptualisation and operationalisation of theories, models and perspectives is, however, not unique. Similar tendencies may also be observed on a global scale (Engelbrecht, 2012). As elsewhere in the world (Bradley, Engelbrecht \& Höjer, 2010), this robust standardisation of supervision can be ascribed to social workers' performance management outputs as part of the South African government's transformational agenda for good-quality service delivery, and the belief that quality assurance of supervision has the potential to have a far-reaching influence on practice (DSD, 2006a). In addition, South African social workers, like their counterparts in other countries, increasingly identify with their agencies rather than with their profession (compare O'Donoghue \& Tsui, 2012; Engelbrecht, 2010b). This results in competing interests rather than striving towards a common goal in practice (Tsui \& Cheung 2004), owing to decreasing central government subsidies, organisational budget cuts and overall austerity measures. These tendencies furthermore result in an excessive emphasis on the administrative function of supervision (Engelbrecht, 2010a) to the detriment of educational and supportive functions in order to adhere to organisational performance management and national accountability systems and statutory requirements. The implication of these neoliberal tendencies for South Africa as for other countries (Bradley et al., 2010; O'Donoghue \& Tsui, 2012) is that despite the marketisation of social service delivery and care as a commodity, the South African Department of Social Development is still enforcing a range of managerial measures (DSD, 2006b; DSD, 2012) in order to maintain control over national standards, of which the supervision framework is one example.

The standardised South African supervision framework could therefore potentially become a primary yardstick for measuring performances of organisations, supervisors and supervisees. Nevertheless, although the quality of supervision and ensuing service delivery is implicitly vouched for in the framework, the quality of supervision is also equated with the management of the framework's standardised operational norms. Therefore the management of these standardised norms inevitably has the potential to become a technical managerial exercise, as the framework ultimately bears some of the main characteristics of managerialism as outlined by Tsui and Cheung (2004:439): the notion is that better management of supervision practices will resolve issues and challenges in supervision; the framework omits elements in supervision that are not quantifiable; and it gives managers carte blanche "to count instead of judge, measure instead of think, and care about the cost instead of the cause". 


\section{RESEARCH METHODOLOGY}

On the basis of the preceding arguments the following research question was formulated: What are the prevailing issues in South African social work supervision? This question was translated into the goal of the research, which was to understand and reflect the voices of social workers despite and beyond the South African supervision framework's standardised norms in order to define some challenges eroding quality supervision and the ultimate "making of music".

To attain the research goal, and after ethical clearance was awarded, the research embarked on a qualitative research methodology with a cross-sectional exploratory and descriptive research design on the basis of the exposition of Grinnell, Unrau and Williams (2005). Non-probability sampling was utilised, because the idea, following Stake (1995), was merely to obtain in-depth data for the opportunity to learn from social workers' experiences and perceptions. Consequently a purposive sample consisting of key informants, according to the description of Schutt (2005), was framed by posting a research question on an open Facebook group for South African social workers with 598 members at the time of the posting. After 60 responses (10.03\% response rate) via email replies were analysed, a saturation point was reached. The inclusion criterion for the sample was registration with the SACSSP as a social worker. The participants were asked to indicate the number of years they have been registered as a social worker and their work status position. A single open-ended question was posed, requiring participants to elaborate extensively on what they regard as contentious issues in the supervision of social workers. In order to analyse the participants' narrative responses into meaningful themes and sub-themes, a seven-step process of the constant comparative analytical template initially developed by Lincoln and Guba (1985) was employed.

Validity of themes, as expounded by Marshall and Rossman (1999), was ensured by adhering to certain parameters in the research process. Primary local and international research was used as a theoretical frame of reference and contextualisation; a criterion for inclusion and the specific Facebook group membership delineated the setting and population of the research; the lived experiences and perceptions of social workers provided answers to the research question; the categorisation of research findings by means of themes and sub-themes extracted from the sample frame's elaborative narratives produced thick descriptions and a comprehensive source of data; and distinct challenges facing quality supervision as the attainment of the goal of the research emerged from the identified themes.

\section{FINDINGS}

The average time that participants have been registered with the SACSSP is 17 years. A total of $31(52 \%)$ supervisees' and 29 (48\%) supervisors' responses were analysed $(\mathrm{N}=60)$. The sample frame's biographical information thus reveals thorough social work experience and an almost equal distribution between supervisors and supervisees. No significant discrepancies between responses of supervisees and supervisors were evident, owing to the nature of the research question and participants' responding 
narratives. A comparison between supervisors' and supervisees' views was also not part of the aim of the study. Therefore participants' responses are presented as an integrated whole, categorised in terms of three main themes that emerged and related sub-themes as follows:

- Theme 1: Training of supervisors

- Sub-theme 1.1: Goal of supervision training

- Sub-theme 1.2: Focus and nature of training

- Sub-theme 1.3: Integrity of the training service provider

- Theme 2: Competencies of supervisors

- Sub-theme 2.1: Leadership role

- Sub-theme 2.2: Administrative function

- Sub-theme 2.3: Educational function

- Sub-theme 2.4: Supportive function

- Theme 3: Structural supervision issues

- Sub-theme 3.2: Workload of supervisors and supervisees

- Sub-theme 3.2: Counterproductive working conditions of supervisors and supervisees

Participants' narratives and sub-themes that emerged are categorised and presented as a synthesis and integrated with the main themes, as comprehensive presentations of narratives and a separate elaboration on each sub-theme are beyond the ambit of this paper. Another significant aspect of the research methodology was that a process consisting of a movement between inductive and deductive logic and reasoning (Sieppert, McMurty \& McClelland, 2005) was used, based on a consistent literature control, which will be presented in the following findings.

\section{Training of supervisors}

The lack of training of supervisors was the theme emphatically repeated by participants. The issue of supervision training is encapsulated in the following excerpt from a participant's narrative:

"Supervisors are not trained as a specialist and rely on their own experiences of being supervised and their practice (social work) experience."

This view is echoed not only by contemporary research findings in South Africa (Cloete, 2012; Engelbrecht, 2010a), but also in other countries (compare Bourn \& HaffordLetchfield, 2011; Carpenter et al., 2012b; Thomas, Propp \& Poertner, 1998). Hair (2012) explicitly refers to repeated recommendations from both practice literature and research that supervision training is necessary for supervisors to provide effective services. This aspect is also emphasised in the South African supervision framework (DSD \& SACSSP, 2012), which requires inter alia that supervisors should attend a supervision course presented by an accredited service provider recognised by the SACSSP. The focus of supervision training and the nature, motives and integrity of the service provider of the training are, however, regarded by the participants as a determining factor in producing quality and highly-skilled supervisors. These viewpoints 
resonate with Hair's (2012) argument that supervision training is often focused on the enhancement of organisational performance when training is left up to agencies and that social work academic programmes (offered by academic institutions) are potentially in the best position to develop sustainable theoretically founded supervision training programmes.

Engelbrecht (2010a) also asserts that within the South African context, a focus of supervision training on the enhancement of organisational performance may easily result in the training of supervisors on how to manage the supervisee to function independently from the supervisor as quickly as possible. Such thinking contradicts the well-articulated goal of supervision as being the need to deliver the best possible service to service users (Kadushin \& Harkness, 2002; Tsui, 2005).

Furthermore, training courses not requiring a practice education component in order for the supervisor to become competent in the integration of the theory and practice of the educational and supportive functions of supervision detract from the training course's academic value and may lead to merely managerial supervision. Issues such as the overall professional competencies of supervisors, specifically around the provision of education and support to supervisees, thus became evident and are examined as a second theme.

\section{Competencies of supervisors}

Within the context of competencies of supervisors and with specific reference to leadership competencies, a participant avers that:

\section{"...they are managing behind closed doors."}

This remark implies a sinister leadership style of supervisors, owing to a lack of skills. In this regard Lawler (2007) refers to calls for improved leadership skills in social work and social care in an English context, which could potentially promote effectiveness and other necessary organisational qualities. He also affirms the argument that a leadership gap gives rise to a skills shortage, which is also applicable within the South African context. Social work was declared a scarce skill in South Africa (DSD, 2006a) and may as a consequence also be regarded as a de-skilled profession in terms of leadership capacity. Research by Engelbrecht (2006) on a brain drain of South African social workers since 1994 shows that a significant number of supervisors migrated and/or left the social work profession, and that these social workers represent a lost leadership generation who may not easily be regained for local social service delivery.

A normative supervision framework may thus be successful in prescribing to supervisors what to do and what not to do, but may be ambiguous about reinstalling leadership by "put(ting) measures in place to pass on a scholarly theoretical body of knowledge as well as tacit practice experience and wisdom to subsequent generations through installing effective supervision practices, in order to convey a competent professional social work heritage to practitioners" (DSD \& SACSSP, 2012:14).

This ambiguous interpretation of leadership is confirmed by a participant within the context of supervisors' fulfilment of supervision functions: 
"Supervision becomes an administration session in order to deal with day-today operations in the office, instead of creatively focusing on the professional development of the social worker. The supervisor just does what she has to do...."

Although this narrative is in agreement with Hair's (2012:12) comment that "a focus on administrative tasks is needed as part of supervision to help social workers maintain accountability to their clients and the workplace", the participant also points to the tension between merely maintaining administrative standards and norms in supervision as required by the supervision framework, and education and support of supervisees, which requires advanced competencies and specific leadership skills beyond the scope of the framework.

The execution of advanced competencies, such as leadership, administration, support and education, finds expression in the actual content of reflective supervision sessions, something that is problematic to circumscribe in a supervision policy or framework. Hence Carpenter, Patsios, Wood, Platt, Shardlow, McLaughlin, Scholar, Haines, Wong and Blewett (2012a) concur that supervision sessions are viewed much more positively where reflective practice is encouraged and where it is considered to be a key element in supervision of newly qualified social workers. This conclusion is confirmed in the narrative of a newly qualified social worker participant, who bluntly declared:

“...I'm young, inexperienced and scared!"

A seasoned participant responded:

"When we debrief once a month, it involves eating out at a restaurant - there is no real awareness of debriefing."

These responses correspond with research findings of Carpenter et al. (2012a) that all supervisees prefer a supportive style of supervision. This also underlines the fact that a simple tick-box exercise about meeting standards and norms of a supervision framework and policy would not be successful in responding to the concerns of the beforementioned newly qualified social worker and seasoned supervisee in need of debriefing. Furthermore, Bourn and Hafford-Letchfield (2011) affirm that stress levels amongst managers may be higher than those of practitioners, supporting research done by Bradley et al. (2010) in England, Sweden and South Africa. These supervisors may detract from quality practice owing to the potential neglect of their core functions. This issue is also not addressed in the supervision framework.

\section{Structural supervision issues}

Although issues related to workload are addressed in the supervision framework, participants' responses confirmed local research findings of Engelbrecht (2010a) as well as English research findings (Carpenter et al., 2012b) that supervision sessions are sometimes cancelled or delayed because supervisors are too busy or supervision is being conducted "on the run" (Noble \& Irwin, 2009:351) and "often focused more on workers completing forms on time rather than on the quality of outcomes for service users" (Bourn \& Hafford-Letchfield, 2011:45). A participating supervisor said, for example: 
"I'm so busy with management tasks and also front-line work that I do not have time to supervise."

Ironically the same South African government department (DSD) that increasingly puts pressure on social service organisations (and ultimately supervisors) in terms of performance, meeting targets and accountability (DSD, 2012), notwithstanding decreasing budgets and fiscal measures, also sets standards for supervisor-supervisee ratios in the supervision framework (DSD \& SACSSP, 2012). This leaves managers with the daunting task of conducting supervision responsible for organisational assets in terms of money, credibility, competition and overall marketisation as well as of conducting supervision focused on the nurturing of supervisor-supervisee relationships conducive to the development of supervisees' professional capacities, staff morale and job satisfaction. Consequently, the supervision framework's envisaged aim to "strike a balance" between the supervision functions of support, education and administration is hardly attainable within the prevailing neoliberal discourse, when the improvement of structural supervision issues such as scarce resources, unmanageable workloads and counter-productive working conditions of supervisors and supervisees is not prioritised as a prerequisite for the establishment of the supervision framework.

It is therefore no surprise that supervision is regarded by some participants as outdated, and not as a highly skilled and specialised professional activity:

"...supervision reminds (me) of a supervisor in a supermarket and is not professional at all.”

Moreover, the mere fact that a normative framework is needed by authoritative organisations and institutions to tell professionals how to supervise each other, but to trust their professional discretion when they intervene in the lives of vulnerable individuals, groups and communities, prompted one participant to react:

“...supervision becomes a babysitting. "

Hence, even the introduction of private sector activities in supervision such as coaching and mentoring (Connor \& Pokora, 2007), with a special focus on relationships in order to enhance performance (Harlow, 2013), simply raises questions on what is the same and what is different in these activities (Engelbrecht, 2012). It seems that structural issues in social service delivery pose such an obstacle that supervision or whatever private sector activity is applied, has no feasible function other than to safeguard standards.

\section{DISCUSSION}

Based on the findings of this research, Kadushin's (1992:230-231) analogy on "playing notes or making music" could be extended by posing the following question: although social work supervision policies and frameworks are apparently playing the required notes, why do we not hear the music? Heard repeatedly from the participants of this study was that the educational and supportive function of supervision is inevitably not regarded as a priority of supervision within the current times of neoliberal discourse but that supervision is in fact being regarded as a priority of effective management. This implies that education and support of supervisees, as generally accepted functions of 
supervision (Kadushin \& Harkness, 2002), are being changed into becoming compliance checking and auditing of adherence to processes. Consequently, the South African supervision framework may be viewed as playing to managerial measures, based on the notion that this framework can be the ultimate answer to "faulty or weak" (Botha, 2002:1) supervision.

Supervision of social workers should be regarded as a means and not an end in order to deliver and not to gain, based on the inherent values and principles of the social work profession as expounded in the profession's international definition (Hare, 2004), which differ fundamentally from those of the market. But the South African supervision framework may also be regarded as a handy management tool, instrumental in demonstrating evidence-based practice. Be that as it may, these evidence-based practices are inextricably tied to the survival of social work institutions, supervisors and supervisees. Hence, the analogy of "playing notes or making music" is indeed more complex than a simple choice and answer, as neoliberal realities appear to be irreversible and dictate the nature of the world in which social work is operating. Within this context of supervision policies and frameworks, and as an endeavour not to end up with a damning "no notes to make music", some challenges regarding the reinstatement of quality supervision are posed, based on the themes which emerged from responses of South African social workers.

\section{CHALLENGES}

The role and contribution of both academic and practice institutions regarding the training of supervisors should not be underestimated in the reinstatement of quality supervision, which is not just a simplistic managerial issue but, as this research shows, is more complex and also inter alia a matter of academic competence and good leadership. Therefore academic institutions in partnership with practice institutions are challenged to introduce or extend supervision training in whatever form, which is holistic and specifically focused on grounded theories, models and perspectives on supervision in order to produce scholarly professionals and not just managerial supervisors who only mechanically "tick the right boxes". As undergraduate social workers are trained at academic institutions to render quality social work intervention, supervisors of those graduates should in turn also receive appropriate academic training to conduct quality supervision. This training embraces not only acquired theoretical knowledge, values and skills, but also integration with practice education and the development of leadership competencies essential to proactively understand, critically analyse, interpret and strategically thwart both the concealed and significant impact of managerialism on the configuration of organisations, supervision, social workers, service delivery and service users. The content of supervision training should, however, take the country's unique welfare policy context and social environment into consideration and should not randomly adopt other countries' body of knowledge on supervision without contextspecific adaptations.

The social work academic and practice fraternity are furthermore challenged to embark on research regarding the utilisation of different models or ways in which the 
constellation of administration, education and support of social workers is being organised in social service organisations (e.g. supervision offered by external and/or internal supervisors; see Bradley et al., 2010) and their impact on social service delivery. Additional research findings on the content of reflective supervision, how to conduct high-quality supervision sessions and the impact that supervision has on service users can likewise add value to supervision policies, frameworks and practice.

\section{CONCLUSION}

The ultimate issue in supervision, despite the introduction of the South African supervision framework as suggested by the research findings, remains the unmanageable workloads and counter-productive working conditions of supervisors and supervisees. The quality of supervision is inextricably dependent on these conditions, and improvement of these issues should be the main priority of any supervision policy and framework. Equally, the ultimate essential attribute of a commendable social work supervision policy and framework is that it should inspire a heritage of leading scholarly professional supervisors, capable of quality supervision that reflects pride in the social work profession in the face of despair, disillusionment and managerial constraints, and which is conducive to social workers' best efforts - thus "making music".

\section{ACKNOWLEDGEMENT}

This research and article were made possible by the support of a Marie Curie Action: International Research Staff Exchange Scheme (contract no. 295203: EU FP7-PEOPLEIRSES, NL_SOCIAL) and co-funding by the South African Department of Science and Technology (DST/CON 0121/2012).

\section{REFERENCES}

AORTEAROA NEW ZEALAND ASSOCIATION OF SOCIAL WORKERS. 2012. Supervision policy. [Online] Available: www.anzasw.org.nz. [Accessed: 03/03/2013].

AUSTRALIAN ASSOCIATION OF SOCIAL WORKERS. 2010. Practice standards for social workers: supervision. [Online] Available: www.aasw.asn.au. [Accessed: 03/03/2013].

BOGO, M. \& McKNIGHT, K. 2005. Clinical supervision in social work: a review of the research literature. The Clinical Supervisor, 24(1/2):49-67.

BOTHA, N.J. 2002. Supervision and consultation in social work. Bloemfontein: Drufoma.

BOURN, D. \& HAFFORD-LETCHFIELD, T. 2011. The role of social work professional supervision in conditions of uncertainty. The International Journal of Knowledge, Culture and Change Management, 10(9):41-55.

BRADLEY, G., ENGELBRECHT, L.K. \& HÖJER, S. 2010. Supervision: a force for change? Three stories told. International Social Work, 53(6):773-790.

BRITISH ASSOCIATION OF SOCIAL WORKERS. 2011. UK supervision policy. [Online] Available: www.basw.co.uk. [Accessed: 03/03/2013]. 
CARPENTER, J., PATSIOS, D., WOOD, M., PLATT, D., SHARDLOW, S., MCLAUGHLIN, H., SCHOLAR, H., HAINES, C., WONG, C. \& BLEWETT, J. 2012a. Qualified Social Worker Programme: final evaluation report (2008 to 2011). [Online] Available: https://www.education.gov.uk/publications/eOrderingDownload/ DFE-RR229.pdf. [Accessed: 03/03/2013].

CARPENTER, J., WEBB, C., BOSTOCK, L. \& COOMBER, C. 2012b. Effective supervision in social work and social care. Social Care Institute for Excellence. [Online] Available: www.scie.org.uk. [Accessed: 03/03/2013].

CLOETE, V. 2012. The features and use of mentoring as an activity in supervision of newly qualified social workers. Stellenbosch: Stellenbosch University. (MA Thesis)

CONNOR, M. \& POKORA, J. 2007. Coaching and mentoring at work. Developing effective practice. Berkshire: Open University Press.

DSD (DEPARTMENT OF SOCIAL DEVELOPMENT). 2006a. Recruitment and retention strategy for social workers. Pretoria: Department of Social Development.

DSD (DEPARTMENT OF SOCIAL DEVELOPMENT). 2006b. Integrated service delivery model towards improved social services. Pretoria: Government Printers.

DSD (DEPARTMENT OF SOCIAL DEVELOPMENT). 2012. Policy on financial awards to service providers. Pretoria: Department of Social Development.

DSD \& SACSSP (DEPARTMENT OF SOCIAL DEVELOPMENT \& SOUTH AFRICAN COUNCIL FOR SOCIAL SERVICE PROFESSIONS). 2012. Supervision framework for the social work profession. Department of Social Development.

ENGELBRECHT, L.K. 2006. Plumbing the brain drain of South African social workers migrating to the UK: challenges for social service providers. Social Work/ Maatskaplike Werk, 42(2):101-121.

ENGELBRECHT, L.K. 2010a. Yesterday, today and tomorrow: is social work supervision in South Africa keeping up? Social Work/Maatskaplike Werk, 46(3):324342.

ENGELBRECHT, L.K. 2010b. A strengths perspective on supervision of social workers: an alternative management paradigm within a social development context. Social Work and Social Sciences Review, 14(1):47-58.

ENGELBRECHT, L.K. 2012. Coaching, mentoring and consultation: the same but different activities in supervision of social workers in South Africa? Social Work/Maatskaplike Werk, 48(3):357-368.

FOUCHÉ, C.B. 2005. Qualitative research designs. In: DE VOS, A.S. (ed) Research at grass roots. A primer for the caring professions. Pretoria: Van Schaik Publishers.

GRINNELL, R.M., UNRAU, Y.A. \& WILLIAMS, M. 2005. Scientific inquiry and social work. In: GRINNELL, R.M. \& UNRAU, Y.A. (eds) Social work research and evaluation. Quantitative and qualitative approaches $\left(7^{\text {th }}\right.$ ed). Oxford: Oxford University Press. 
HAIR, H.J. 2012. The purpose and duration of supervision, and the training and discipline of supervisors: what social workers say they need to provide effective services. British Journal of Social Work, 1-27 (doi: 10.1093/bjsw/bcs071)

HARE, I. 2004. Defining social work for the $21^{\text {st }}$ century. The International Federation of Social Workers' revised definition of social work. International Social Work, 3(47):406-424.

HARLOW, E. 2013. Coaching, supervision and the social work Zeitgeist. Practice: Social Work in Action, 25(1):61-70.

KADUSHIN, A. 1992. Supervision in social work $\left(3^{\text {rd }}\right.$ ed). New York: Columbia University Press.

KADUSHIN, A. \& HARKNESS, D. 2002. Supervision in social work $\left(4^{\text {th }}\right.$ ed $)$. New York: Columbia University Press.

LAMBLEY, S. 2010. Managers: are they really to blame for what's happening to social work? Social Work and Social Sciences Review, 14(2):6-19.

LAWLER, J. 2007. Leadership in social work: a case of caveat emptor? British Journal of Social Work, 37:123-141. (doi:10.1093/bjsw/bch404).

LINCOLN, Y. \& GUBA, E. 1985. Naturalistic Inquiry. Beverly Hills: Sage Publications.

MARSHALL, C. \& ROSSMAN, G.B. 1999. Designing qualitative research $\left(3^{\text {rd }}\right.$ ed). London: Sage Publications.

NOBLE, C. \& IRWIN, J. 2009. Social work supervision: an exploration of the current challenges in a rapidly changing social, economic and political environment. Journal of Social Work, 9(3):345-358.

O'DONOGHUE, K. \& TSUI, M.S. 2012. Towards a professional supervision culture: the development of social work supervision in Aotearoa New Zealand. International Social Work, 55(1):5-28.

RSA (REPUBLIC OF SOUTH AFRICA). 1978. Social Service Professions Act, Act 110 of 1978. Pretoria: Government Printers.

RSA (REPUBLIC OF SOUTH AFRICA). 2006. Children's Act, No.38 of 2005. Government Gazette, vol. 492, 19 June. No 28944. Cape Town.

SACSSP (SOUTH AFRICAN COUNCIL FOR SOCIAL SERVICE PROFESSIONS). 2007. Policy guidelines for course of conduct, code of ethics and the rules for social workers. [Online] Available: http://www.sacssp.co.za/website/wp-content/uploads/ 2012/06/Code-of-Ethics.pdf. [Accessed: 03/03/2013].

SCHUTT, R.K. 2005. Sampling. In: GRINNELL, R.M. \& UNRAU, Y.A. (eds) Social work research and evaluation. Quantitative and qualitative approaches $\left(7^{\text {th }} \mathrm{ed}\right)$. Oxford: Oxford University Press. 
468

SIEPPERT, J.D., McMURTY, S.L. \& McCLELLAND, R.W. 2005. Utilizing existing statistics. In: GRINNELL, R.M. \& UNRAU, Y.A. (eds) Social work research and evaluation. Quantitative and qualitative approaches $\left(7^{\text {th }}\right.$ ed). Oxford: Oxford University Press.

STAKE, R. 1995. The art of case study research. Thousand Oaks: Sage Publications. THOMAS, K.G., PROPP, J. \& POERTNER, J. 1998. The supervisor's role in the transfer of training. Administration in Social Work, 22(1):1-18.

TSUI, M.S. 2005. Social work supervision. Contexts and concepts. London: Sage Publications.

TSUI, M.S. \& CHEUNG, F.C.H. 2004. Gone with the wind: the impacts of managerialism on human services. British Journal of Social Work, 34(3):437-442.

Prof Lambert Engelbrecht, Department of Social Work, Stellenbosch University, Stellenbosch, South Africa. 